\title{
The State and Cause of Psychological Changes Seven Years after the Great East Japan Earthquake
}

Akiko Sakai ${ }^{\star}$, Takako Shimizu, Akihisa Sakai, Chie Isomi, Satomi Shigeta and Kazumi Tsukida

College of Nursing, Faculty of Medical Sciences, University of Fukui, 23-3 Matsuokashimoaizuki, Eiheiji-cho, Yoshida-gun, Fukui 910-1193, Japan

\section{Abstract}

The aim of this study is to determine the psychological state and the cause of any changes in the psychological state of survivors of the Great East Japan Earthquake (GEJE) seven years after the event. The GEJE was a catastrophic disaster that struck a wide area eastern Japan. As a result, victims needed to live in shelters or temporary housings for a prolonged period. Consequently, many elderly who had been affected lost hope or had difficulty reconstructing their lives, with many eventually choosing to commit suicide or to die alone. These effects reveal a complicated process of psychological recovery and chronic distress. This study, therefore, provides a longitudinal examination of the psychological state of GEJE victims over the course of 7 years, both individually and collectively. We sampled 10 victims of the GEJE, asking them to draw a line describing the transition of their psychological state and then to describe specific episodes in which they were aware of changing in their psychological state. We subsequently found four patterns of psychological transition among victims in this study. Moreover, we found that victims' psychological state was prone to change when triggered by circumstance in living, health status, and their relationship with their community.

\section{Introduction}

The Great East Japan Earthquake (GEJE), a 9.0 magnitude earthquake, occurred on March 11, 2011. This was the biggest recorded earthquake in Japan's history and the resultant tsunami devastated massive areas of the country. Scores of people were injured or suffered from severe psychological trauma due to the grand scale of the damage brought about by the event [1-3]. The psychological damage that results from natural disasters is often chronic, which may explain why the psychological effects of the GEJE are still apparent 8 years after the earthquake [4-6].

The most serious psychological problems known to occur in the wake of the GEJE include people dying alone or committing suicide. Although each victim shows an idiosyncratic cluster of symptom, the main triggers include community loss or dilution, environments likely to trigger isolation, stress disorder, or a deterioration of in mental health due to the changes in living circumstances [7].

Raphael [8] identifies five phases of response in disaster psychiatry: warning, impact, honeymoon (post-impact), disillusionment, and returning to community and individual attachment (i.e., recovery) Disillusionment, however, can also appear due to chronical stress, which can trigger a psychological second disaster. Moreover, Austin [9] argues that the distinction between acute and chronic responses can be made within 3-4 months, although the severity and duration of responses can differ between individuals. Notwithstanding, there is no real consensus among researchers as to the duration before a response is considered chronic.

Following the Great Hanshin-Awaji Earthquake in 1995, approximately $10 \%$ of victims who remained in temporary housing for approximately 3 years after the earthquake were diagnosed with Post-Traumatic Stress Disorder (PTSD) [10,11]. Eleven years after the event, however, most had experiences a resolution of symptoms [12]. On the other hand, $11 \%$ victims suffered from PTSD 2.5 years after the 2004 Sumatra Earthquake [13]. While 19.3\% of victims suffered from PTSD 4 years after the 2008 Sichuan Earthquake, approximately $10-20 \%$ of people both inside and outside the country were diagnosed with PTSD within 2-4 years [14]. According to Arnberg et al. [15], after 6 years, $11.3 \%$ of people were found to present with PTSD, while this figure had dropped to only $4.2 \%$ after 9 years. However, most longitudinal studies of psychological damage only track participants for 5 years. Therefore, this study makes a significant to the disaster psychiatry literature as we trace the transition and cause of psychological damage to victims from the GEJE 7 years after the disaster. The findings of this study can help to prepare for future disasters in terms of the planning for long-time psychological support.

\section{Objectives}

This aim of this study is to identify the cause of transitions in the psychological state of victims of the GEJE 7 years after the disaster.

\section{Methods \\ Participants}

Ten elderly victims of the GEJE, living in Iwate and Miyagi prefectures (aged 60-90 years, 5 male, and 5 female) were recruited as participants in this study. At the time of recruitment, each participant was either living in their own apartment or had built a new house after having lost their former home, either by having it pulled down or destroyed by the tsunami and having lived in temporary accommodation for a period. Data was collected in either February or March every year for 7 years.

\section{Materials}

The participants were asked to draw a line showing fluctuations in their psychological state from the time of the disaster and to describetheir experiences of the disaster. Using a semi-structured

"Corresponding Author: Prof. Akiko Sakai, College of Nursing, Faculty of Medical Sciences, University of Fukui, 23-3 Matsuokashimoaizuki, Eiheiji-cho, Yoshidagun, Fukui 910-1193, Japan; E-mail: sakaiaki@u-fukui.ac.jp

Citation: Sakai A, Shimizu T, Sakai A, Isomi C, Shigeta S, et al. (2019) The State and Cause of Psychological Changes Seven Years after the Great East Japan Earthquake. Int J Nurs Clin Pract 6: 308. doi: https://doi.org/10.15344/23944978/2019/308

Copyright: (C) 2019 Sakai et al. This is an open-access article distributed under the terms of the Creative Commons Attribution License, which permits unrestricted use, distribution, and reproduction in any medium, provided the original author and source are credited. 
Citation: Sakai A, Shimizu T, Sakai A, Isomi C, Shigeta S, et al. (2019) The State and Cause of Psychological Changes Seven Years after the Great East Japan Earthquake. Int J Nurs Clin Pract 6: 308. doi: https://doi.org/10.15344/2394-4978/2019/308

Page 2 of 8

interview, participants were also asked to explain any fluctuations and their potential causes. This technique of drawing a line to help visualize one's psychological state was originally described by Rafael [16] for determining the phase of someone's disaster reaction, and by Selye [17] to plotting responses to stress. This technique has also been utilized to examine the psychological state of survivors of the 2004 Sumatra Earthquake.

The line graph is printed on an A4 sheet $(210 \mathrm{~mm} \times 297 \mathrm{~mm})$, with the vertical axis showing stress reactions, while the horizontal axis describes time. The axis of the stress reaction on the sheet is $10 \mathrm{~cm}$ long on the vertical axis, and a red line was drawn horizontally at the point of the peak of psychological stress levels. A dotted horizontal line was also drawn on the graph in order to mark the level of psychological stability. Participants were instructed to identify the data of major life events or changes in the lifestyle, such as moving into temporary housing, in order to confirm retrospective histories.

Moreover, the researcher interviewed the participants about their thoughts and the details of each episode that they had identified in a bid to understand the events that triggered fluctuation in their psychological state. Participants were instructed to start with any event at any time from their experiences, encouraging them to reflect upon the most traumatic or memorable events, which helped them to recal events more clearly. The interview took approximately 1-hour, and if the participant consenter, audio recordings of the interviews were made. In addition, the researcher kept research diary into which they made notes about the interviews. This method helped participants to find a sense of meaning in their experiences, either by themselves, by drawing the line, or by recalling their episodes.

\section{Design}

The analysis of the lines drawn by participants was performed both individually and collectively. Collective analysis examined the lines of all the participants and described the pattern of psychological change. On the other hand, in the individual analysis, major events on the lines during the first year (e.g., staying in a shelter), forth year (e.g., temporary housing), and seventh year (e.g., own housing or built new house) were examined for each participant.

\section{Ethical considerations}

This study was conducted with the approval by the Ethical Committee of the School of Medical Sciences, University of Fukui
(No. 20180024). Participants were instructed that they had the right to withdraw from the study at any time. Moreover, while participants were informed that the interviews would be stopped if they felt unwell or distressed during the interviews while recalling past events, none of the participants took advantage of this offer. All data obtained from participants during the course of this study was maintained as confidential by the researchers. After the study, all data (including documentation and voice data) was discarded and the memory stick used in the research was erased.

\section{Results}

1. Corrective analysis of transitions in the psychological state of participants 7 years after the earthquake. After examining the lines of all 10 participants simultaneously, we found that none of the lines continued to rise until seventh year (Figure 1). The general trend in these lines was to drop to a point of stability by the second and fifth years. Two participants lost their families during the GEJE. Their lines reflected consistently higher levels of stress until the fifth year, whereupon their lines began to indicate stability. On the other hand, two other participants in the sample indicated consistently low levels of stress throughout the entire study. Consequently, we identified four general trends or patterns in the process of psychological recovery: (a) participants often reached stability by the second year (Figure 2), (b) reaching stability level at the fifth year (Figure 3), (3) maintaining low levels of stress level (Figure 4), and (4) maintaining higher levels of stress (Figure 5).

2. Individual analysis on the transition of psychological state during 7 years after the earthquake. The psychological state of each participant was analyzed individually with respect to aforementioned four patterns or trends in the psychological recovery process. We examined the line patterns for the first, fourth, and seventh years simultaneously.

\section{Pattern 1}

Four participants exhibited this characteristic pattern. A shift in the living circumstances of Participant A triggered a shift in their psychological state toward stability (Figure 6). Participant A had left the shelter early and was already living in temporary housing by the end of the first year. He described this episode thus:

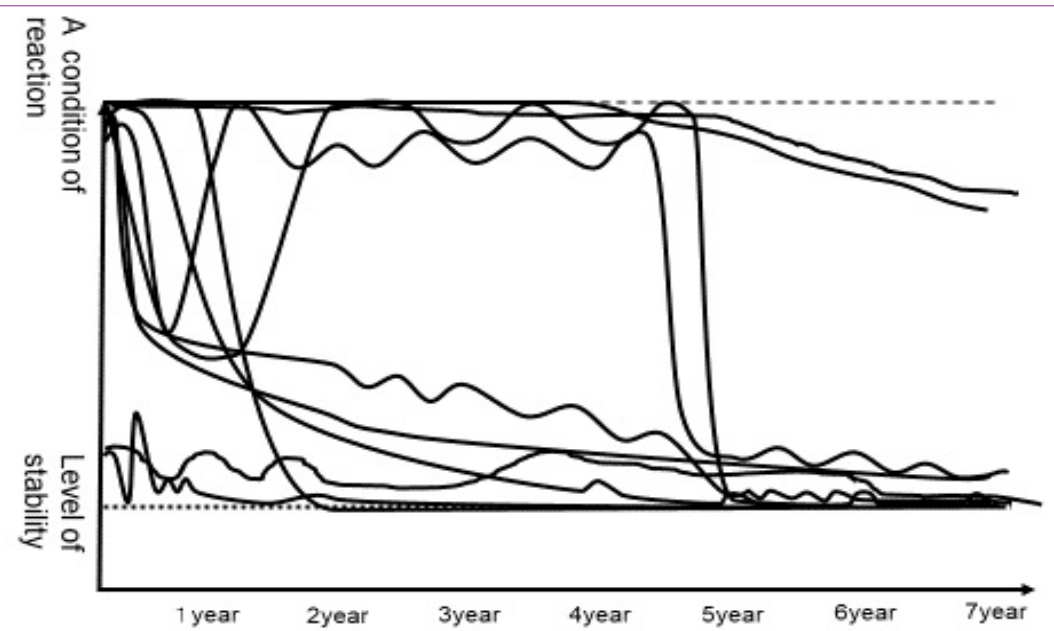

Figure 1: The line of psychological change of victims 7 years after the disaster (10 participants). 
Citation: Sakai A, Shimizu T, Sakai A, Isomi C, Shigeta S, et al. (2019) The State and Cause of Psychological Changes Seven Years after the Great East Japan Earthquake. Int J Nurs Clin Pract 6: 308. doi: https://doi.org/10.15344/2394-4978/2019/308

I put a mat on the hard floor at the shelter and slept in daily bouts with two blankets. I had a bad back so it started aching. It was a terrible experience. I also started to have problems with my heart. Since we did not have enough space to sleep comfortably, I had to be very close to the people next to me while I was sleeping. It was a stressful time.

\section{During their fourth year of living in temporary housing:}

There were familiar people around me and the doors of every house was left open all the time. So we would greet each other regularly. Life in the shelter was too stressful, but I started feeling comfortable after having moved into temporary housing.

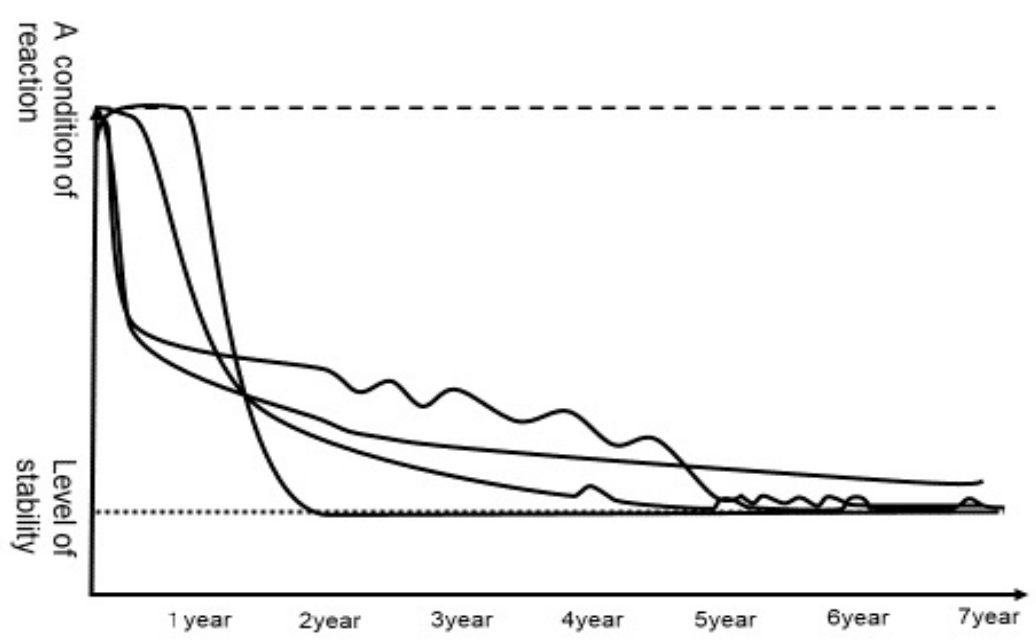

Figure 2: The line of psychological change of victims 7 years after the disaster (Pattern 1).

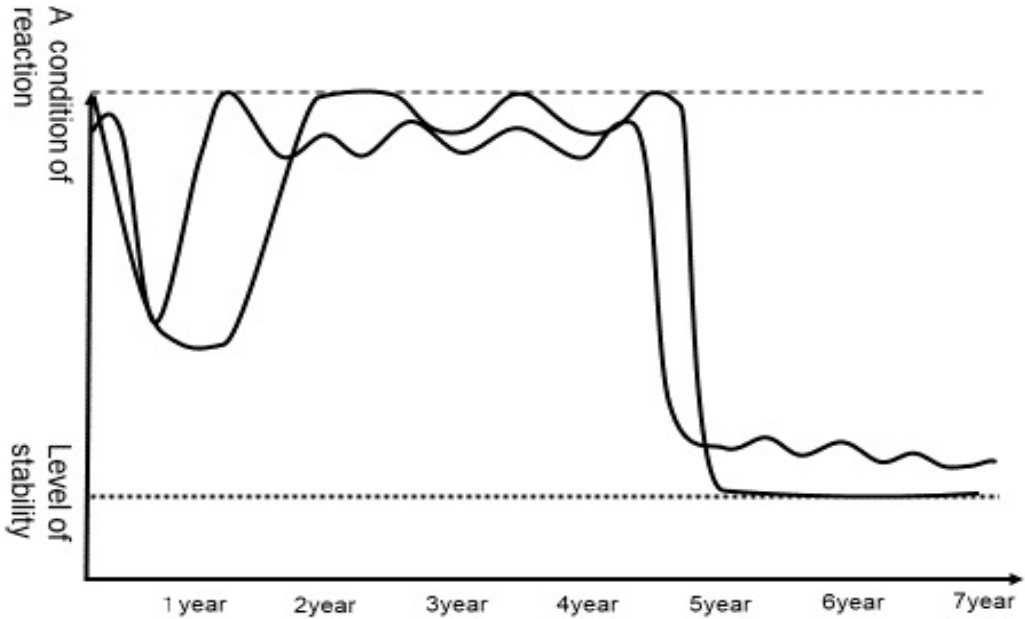

Figure 3: The line of psychological change of victims 7 years after the disaster (Pattern 2).

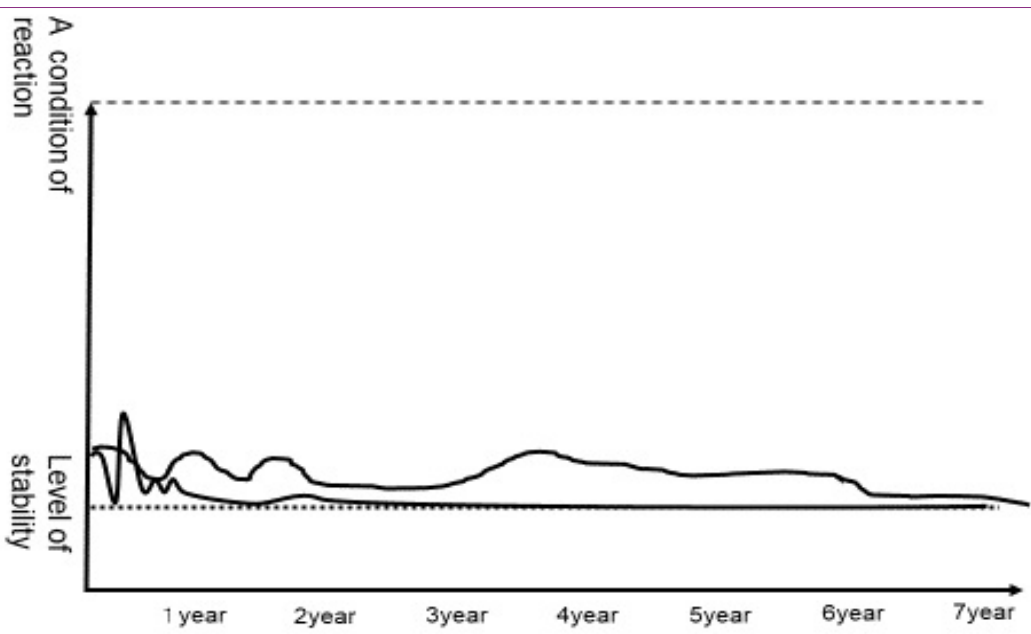

Figure 4: The line of psychological change of victims 7 years after the disaster (Pattern 3) 
Citation: Sakai A, Shimizu T, Sakai A, Isomi C, Shigeta S, et al. (2019) The State and Cause of Psychological Changes Seven Years after the Great East Japan Earthquake. Int J Nurs Clin Pract 6: 308. doi: https://doi.org/10.15344/2394-4978/2019/308

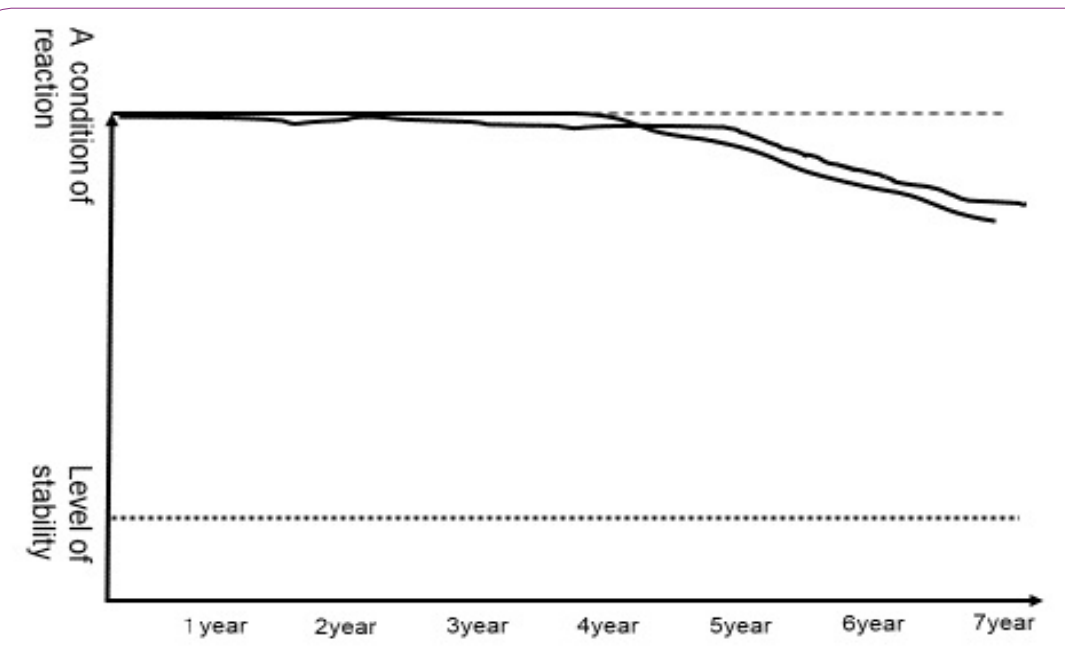

Figure 5: The line of psychological change of victims 7 years after the disaster (Pattern 4).

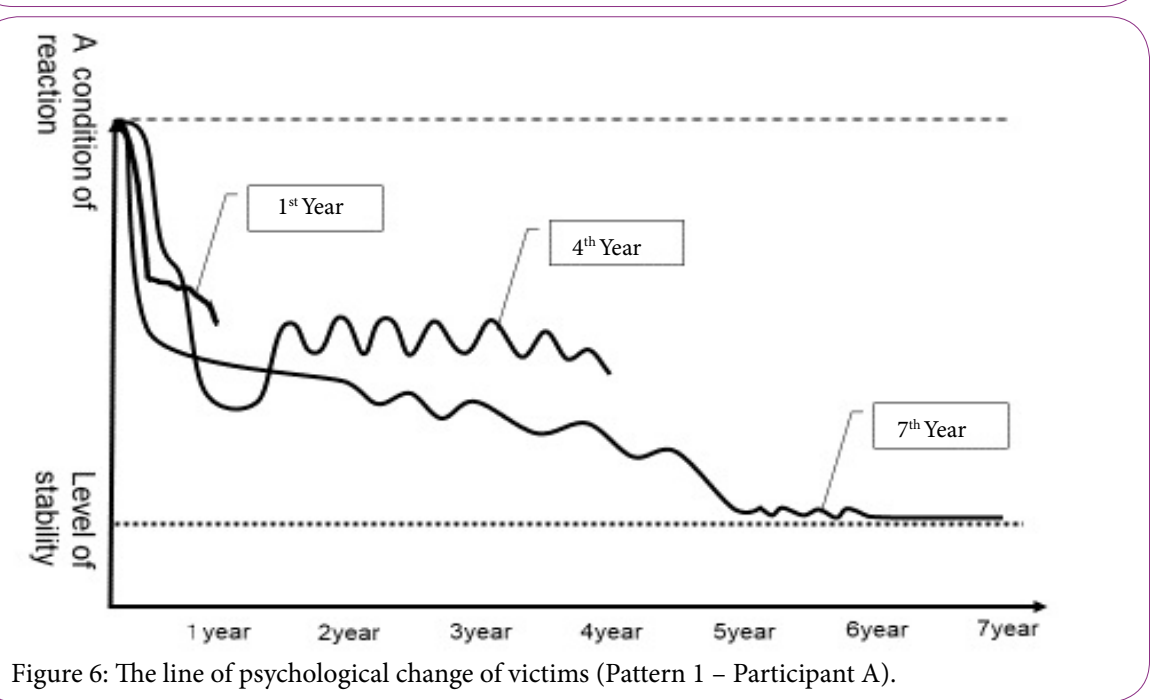

By the seventh year, Participant A had moved into his own apartment, and said: "There are two tea gatherings every month here. Most of the people come to the event." At the time of being interviewed, Participant A was looking forward to their next monthly gathering.

\section{Pattern 2}

Two participants in this study described having achieved stability by their fifth year. Participant B's stress levels fluctuated in responses to changes in the condition of their health and the state of housing reconstruction (Figure 7). Participant B had also moved out of the shelter and was living in temporary housing by the end of the first year. He talked about the changes due to the disease, as well as the loss of his career and role:

I never felt relaxed at the shelter. After I moved to a temporary housing, I was diagnosed with pancreatic cancer, which made me very depressed. I would have felt more relieved if I had a job, but the cancer makes me tire easily all the time.

By the fifth year, Participant B had rebuilt his house, after which he stated:

I felt more relaxed than I did when I was still in the temporary housing. Living in my own house has made me feel better. Living in the temporary housing was the most stressful time.
By the seventh year, he said; "I feel my life is stable, but it will never be happy enough. I guess that this feeling will continue."

\section{Pattern 3}

Two participants exhibited consistently low stress levels throughout the entire study. Participant $\mathrm{C}$ attributed his resilience to his previous wartime experiences, the reconstruction of his house, and living with his family (Figure 8). Participant $\mathrm{C}$ also moved out of the shelter and was living in temporary housing by the end of the first year.

I experienced before, during and after the war. And I do not feel stressed too much at this age. Since my friends and students come visit me, I am thinking to build a small house on the mountain. People at this time are too needy. People can work things out without something like air conditioner and food.

Participant C's psychological state fluctuated somewhat during the fourth year when he was physically unwell. However, he made a psychological recovered after he started living with his son during the seventh year.

\section{Pattern 4}

Two participants showed particularly high stress levels. For Participant D, the loss of her son and changes in the structure of her 
Citation: Sakai A, Shimizu T, Sakai A, Isomi C, Shigeta S, et al. (2019) The State and Cause of Psychological Changes Seven Years after the Great East Japan Earthquake. Int J Nurs Clin Pract 6: 308. doi: https://doi.org/10.15344/2394-4978/2019/308

family increased her stress levels (Figure 9). Nonetheless, despite persistently high stress levels for 212 years as measured in the fourth year of the study, and for four years by the time of the seventh year Participant D did eventually experience a reduction in their stress levels. In the first year after the earthquake, Participant D mentioned: I do not understand why only my son had to die. He had been working out a lot and was able to run fast. I still wash, iron, and hang his uniform every day, 365 days a year.

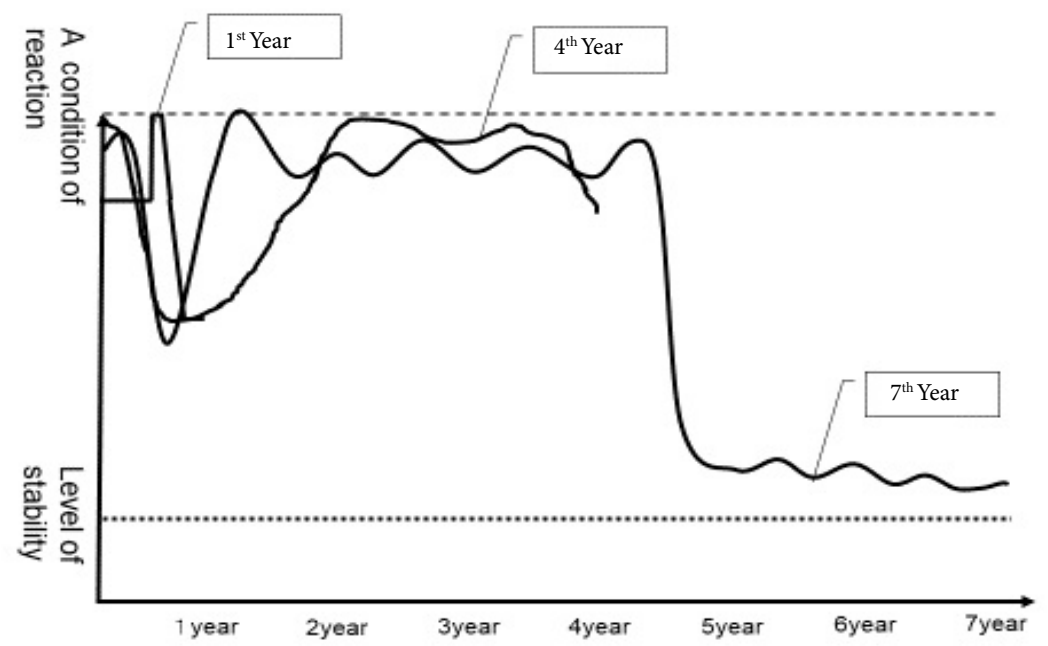

Figure 7: The line of psychological change of victims (Pattern 2 - Participant B).

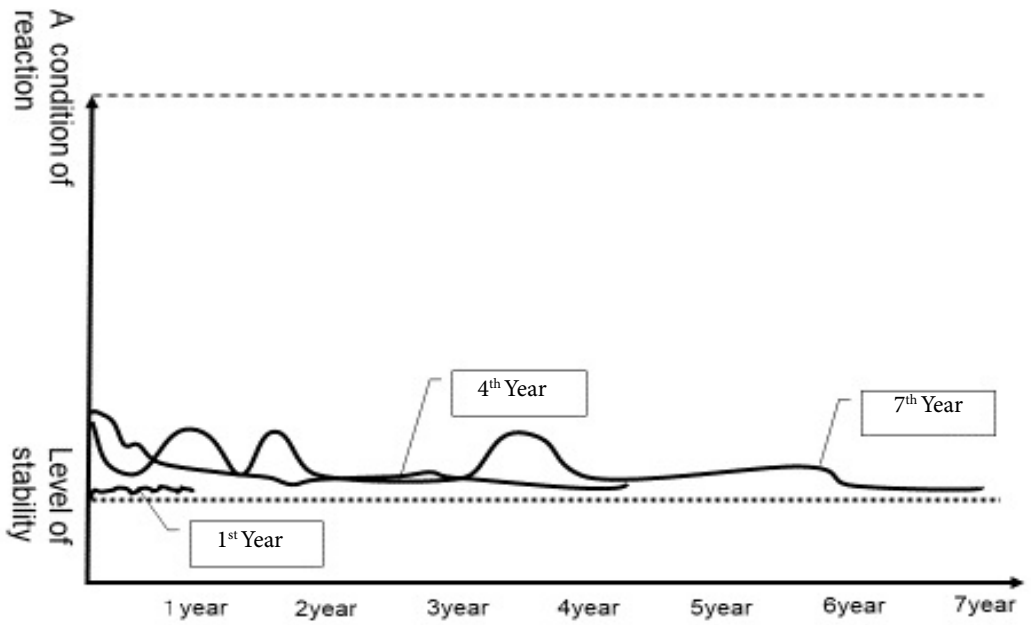

Figure 8: The line of psychological change of victims (Pattern 3 - Participant C).

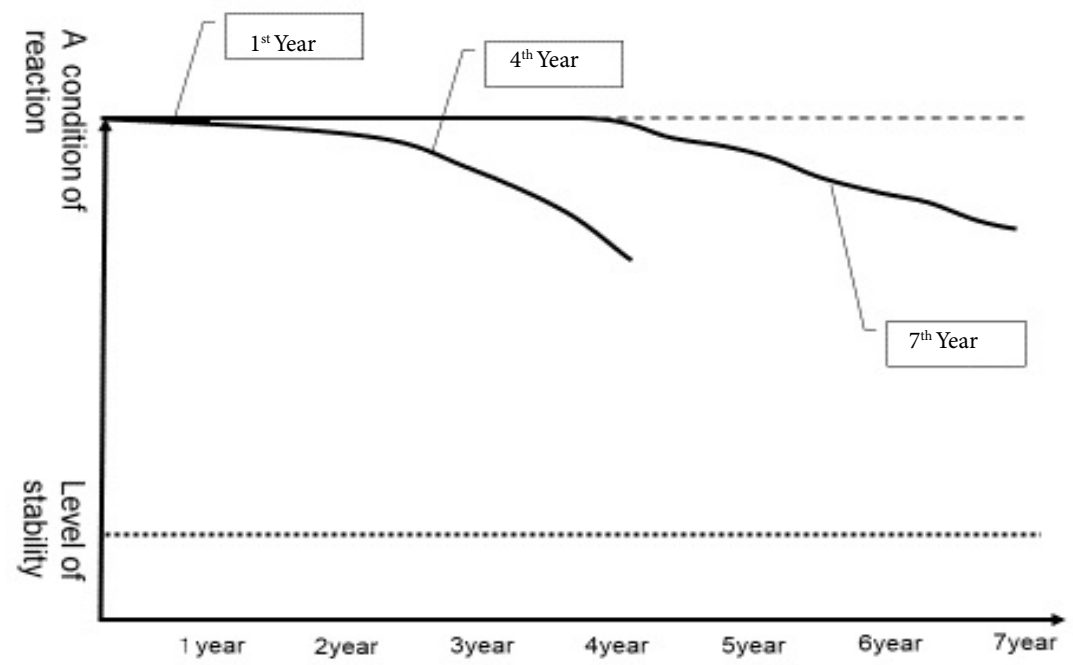

Figure 9: The line of psychological change of victims (Pattern 4 - Participant D). 
Citation: Sakai A, Shimizu T, Sakai A, Isomi C, Shigeta S, et al. (2019) The State and Cause of Psychological Changes Seven Years after the Great East Japan Earthquake. Int J Nurs Clin Pract 6: 308. doi: https://doi.org/10.15344/2394-4978/2019/308

By the fourth year, she begun to consider the meaning of her son's death:

I was lucky that I found my son, some people are still missing. My husband did not talk with him much before he died, but he goes to his son's grave every week. And I still remember the last time I saw his face with his mouth wide open in a plastic bag. He might have been shouting to people to escape.

By the seventh year, she was talking about her past with her son:

I regret that I could not listen to what he wanted to talk about with me while I was busy. But he appeared in my dream and said not to worry about it because he does not mind.

In the first year, she was not communicating much with her husband, nor did she take time to see his mother. However, her husband told the researcher that she had been looking forward to seeing the researcher. By the seventh year, her husband's psychological state had begun to fluctuate somewhat more than her own.

\section{Discussion}

The aim of this study was to clarify the cause of transitions in the psychological state of victims of the GEJE 7 years after the disaster Four patterns of transition in the psychological state of victims could be identified across the span of 7 year after the earthquake. In patterns 1 and 2, dramatic changes were seen in the psychological state of survivors, eventually reaching a point of stability after 2 and 5 years, respectively. These changes were associated with changes in the living situation of survivors. For example, most of the survivors had moved out from their shelters into temporary housing by their second year; moreover, most had also moved from temporary housing into their own apartments or had rebuilt their own homes by the fifth year. Participants with lines consistent with patterns1, 2, and 4 showed the highest stress levels when they were living in the shelter. Participants with lines consistent with Pattern 3, however, maintained consistently low stress levels throughout the entire study period, although exhibited some fluctuation in their psychological state during their first year of living at the shelter. We can thus conclude that the poor environment of the shelter might affect more on the psychological state of all participants.

One thing that became apparent throughout the study was the importance of survivors' living situation in influencing their psychological state. Specifically, the poor environment of the shelter caused a range of psychological problems among participants. Most of the designated shelters were public facilities, such as elementary schools; therefore, victims have to survive in a poor environment with hard flooring and no proper air conditioning. In the immediate aftermath of the disaster, the sheer number of victims forced to take up residence in these shelters left most survivors with little in the way of living space or privacy. As such, these living conditions were a significant source of stress for most of the participants in this study. Moreover, the shelters were not a guarantee of safety, with many survivors still facing an uncertain time in relation to the prospect of death from diseases such as tsunami lung; overstretched medical resources leading to deaths from chronic, but otherwise manageable, illnesses; respiratory diseases (e.g., pneumonia and asthma); as well as the stress of aftershocks. Japan's official disaster plan calls for shelters to be made available for use for 7 days after a major disaster; however, after the GEJE, the scope of the disaster meant that many of these sheltered remained in constant use for at least 8 months. Consequently, many of the participants in this study exhibited a deteriorating psychological state consistent with the duration of their stay at the shelter.

That said, participants who had rebuilt their homes by the fifth year had gained psychological stability after having moved out of temporary housing and resuming their own lives in their own homes. Therefore, we can see a consistent pattern of stress as a result of life in temporary housing. While temporary housing provides the survivor with some relief from the stressors of shelters never designed for long-term human residence, the temporary nature of such housing is itself a source of stress for some survivors. This is especially true for victims who might have lost their desire to live due to the loss of family members and their homes, for elderly victims who might have difficulty with independent living, or who simply feel a lack of security at not having a place or a community they can call home. Consequently, after moving out from their temporary housing, some survivors have been known to die alone in their new homes without solidifying connections with their new (or resumed) community.

According to Tanaka [11], the number of victims who die alone 1 year after moving into the temporary housing often peaks in the second year. While conventional wisdom might suggest that this melancholy is the product of prolonged unsecured living among elderly victims, this study has found that the stress levels of survivors remains consistently high even after moving into temporary housing. Therefore, the condition of the survivor's housing and the timeline of their transition between different living environments may be closely related to fluctuations in their psychological state.

Furthermore, physical problems are also associated with psychological well-being. After experiencing a catastrophic disaster, many elderly victims experienced a severe deterioration in their pre-existing health problems due in part to problems pertaining to the poor shelter environment or design of temporary housing. Prolonged psychological stress also weakens the immune system and predisposes the individual to an exacerbation of their physical problems, which in turn contributes to a deterioration in their mental health problems. Participant C, for example, who had low stress levels throughout most of the study period, exhibited a temporary onset of psychological problems in response to a physical illness. In the wake of the 1995 Great Hanshin Earthquake, many survivors who had been taking routine medications prior to the earthquake reported having discontinued their medications afterwards. Over time, these survivors became increasingly aware of their deteriorating physical health, losing confidence in their physical condition, which in turn affected their mental state [19]. Therefore, some of environmental adjustment is necessary to prevent psychological deterioration.

Furthermore, personal (e.g., family) and community relationships affect the psychological state of survivors. Two victims whose lines were consistent with Pattern 4 had lost their family members during the GEJE and showed higher levels of stress. In both cases, these high stress levels persisted for at least 4 years, suggesting that the stress had not only became chronic, but that it might have had a serious impact on their daily lives. Selye [17] describes this period of high stress while experiencing the disaster and experiencing prolonged fear over several years as an attempt to balance anxiety and hope, something that he called the "Tiredness (alarm period)". In other words, the adrenal cortex initially excludes all granules, including the cortical hormones themselves, thus allowing for the expression of 
Citation: Sakai A, Shimizu T, Sakai A, Isomi C, Shigeta S, et al. (2019) The State and Cause of Psychological Changes Seven Years after the Great East Japan Earthquake. Int J Nurs Clin Pract 6: 308. doi: https://doi.org/10.15344/2394-4978/2019/308

alarm reactions. However, the adrenal cortex also becomes saturated with an unusually high level of lipid droplets, which in turn triggers a period of resistance. Over time, these lipid droplets are metabolized, and the subsequent absence of lipid droplets necessitates a move to the alarm period, the loss of resistance, and eventual exhaustion. This pathological process can subsequently trigger a cascade of psychiatric symptoms, especially feelings of helpless and bereavement, symptoms typically associated with Post-Traumatic Stress Order (PTSD) [20]. Experiencing the death of familiar people, such as family members, prolongs this state of psychological distress, reducing resistance further. It is therefore necessary to identify and measure this alarm period.

This study, however, also found that family support reduces stress levels. Living with family (Participant C), support from family (Participant D), and communication with familiar people living in the same apartment building (Participant A) can help to prevent stress from becoming chronic. Herman [21] argued that the most effective recovery route involved an initial focus on self-recover and before moving on to create a community of similarly recovering individuals. Therefore, recovery from stress is closely related to one's relationship with other individual [22-24]. Consequently, from the acute phase through to recovery, the need to create a community for victims in which survivors provide psychological support for one another should be regarded as necessary.

Finally, the individual analysis of the transition in participants psychological state revealed clear differences in the pattern of transition and in participant stress levels at 4 and at 7 years after the disaster. We asked survivors to make assumptions about their own psychological state for the purposes of data collection. Not withstanding, the assumptions made by participants were ultimately based on their current psychological state as a point of reference. Therefore, in order to understand changes in their psychological state, it was important not only to understand their current experiences, but recognize the inadequacy of a single psychological state line as a tool for measuring participants' psychological state.

\section{Limitations and Recommendations}

The original aim of this study was to investigate the process of psychological recovery by examining the psychological state line and episode content of a sample of survivors of the GEJE. Individual data was compared longitudinally along a data collection timeline, which was also unique in this study. However, we would argue that it is impossible to draw accurate conclusion about the phased of someone's psychological recovery using a single psychological state line. Scrutinizing the process of psychological recovery from depression and stress has elucidated a protracted recovery process, with is taking several years until aching psychological stability. Notwithstanding, this process may help to differentiate between chronic stress as either a disease or a disorder. This study found that participants were clearly subject to the influences of aging, which affected their physical and psychological well-being. We can this assume that the process of reconstructing their lives would be very stressful for them. Moreover, as most of the participants recognized the fact that they themselves had not fully recovered from their brush with disaster, we aim to continue longitudinal data collection for further investigation. Future studies, therefore, will continue to analyze the cause of fluctuations in the psychological state of participant, and how these might contribute to survivors dying alone or committing suicide. Future studies should also look to increase the number of participants from various backgrounds and with a range of psychological stress-related problems, such as bereavement, to determine how their lifestyles and process of community reconstruction influences their wellbeing. The authors of this study recommend the sustained provision of longitudinal psychological support victims to prevent them from dying alone or committing suicide.

\section{Conclusion}

This study identified four patterns of psychological transition among victims of the GEJE. While we found distinct patterns of fluctuation across the spectrum of these patterns, each pattern nonetheless reached stability eventually at some point throughout the 7 years that followed the GEJE. Pattern 1 reached stability in the second year, Pattern 2 in the fifth year, while Pattern 3 showed stability throughout the entire study. Pattern 4 showed high levels of distress throughout the study period. We also found that fluctuations in the psychological state of victims were triggered by changes in their living circumstance, health status, and relationship with community and families.

\section{Competing Interests}

The authors declare that they have no competing interests.

\section{Acknowledgments}

On behalf of researchers, we would like to express our deepest appreciation for the kind cooperation of the victims of the Great East Japan Earthquake.

\section{Funding}

This study was part of a research project funded by a JSPS Grantin-Aid for Scientific Research (C) 2009-2018 This study was part of a research project funded by a JSPS Grant-in-Aid for Scientific Research (C) 2009-2018.

\section{References}

1. Kumasaka S, Adachi T (2015) The psychological and social situations of supporters and vulnerable people in the Great East Japan Earthquake: Results from the hearings from the supporter. Journal of Developmental Science 15: 19-31.

2. Matsumoto K, Sakuma A, Ueda I, Nagao A, Takahashi Y (2016) Psychological trauma after the Great East Japan Earthquake. Psychiatry Clin Neurosci 70: 318-331.

3. Murosaki Y (2017) Overview of Great East Japan Earthquake. In: Sakai A Kikuchi S (Eds) Nursing Disaster, Nankodo. Japan, pp. 254-259.

4. Sakai A (2012) A study of the process of the change on mental status between the early stage after the disaster and the revival stage in the Great East Japan Earthquake. 1st Research Conference of World Society of Disaster Nursing. 113

5. Sakai A (2014) A Study of the Meaning of Discourse on Disaster Experiences for Victims of the Great East Japan Earthquake. 3rd Research Conference of World Society of Disaster Nursing. 96.

6. Sakai A (2018) Psychological changes of victims from the Great East Japan Earthquake during 7-year after the occurrence and its causes. 5th Research Conference of World Society of Disaster Nursing. 59.

7. Japan Support Center for Suicide Countermeasures, Ministry of Health, Labor and Welfare (2017) The number of people who committed suicide.

8. Raphael B (1986) When Disaster Strikes: How Individuals and Communities Cope with Catastrophe, New York, Basic Books, USA.

9. Austin LS (1996) Responding to Disaster: A Guide for Mental Health Professionals. Virginia: American Psychiatric Press, USA. 
Citation: Sakai A, Shimizu T, Sakai A, Isomi C, Shigeta S, et al. (2019) The State and Cause of Psychological Changes Seven Years after the Great East Japan Earthquake. Int J Nurs Clin Pract 6: 308. doi: https://doi.org/10.15344/2394-4978/2019/308

10. Kato H, Iwai K (1998) Posttraumatic stress disorder after the Great HanshinAwaji Earthquake: assessment by the structured interview to the survivors. Hyogo Prefectural Center for Mental Health and Welfare. 27-35.

11. Tanaka M, Takahashi C, Ueno Y (2010) The conditions of "isolated death" occurrences and its background in public temporary housing for disaster -case of Great Hanshin-Awaji Earthquake. The Architectural Institute of Japan's Journal of Architecture 75: 1815-1826.

12. Goto T (2007) Community mental health after a catastrophic disaster: the psychological health, help-seeking, and traumatic experiences of Kobe residents 11 years after the earthquake. Japanese Bulletin of Traumatic Stress Studies 3: 1-24.

13. Hussain A, Weisaeth L, Heir T (2011) Psychiatric disorders and functional impairment among disaster victims after exposure to a natural disaster: A population based study. J Affect Disord 128: 135-141.

14. Dongling L, Hui C, Ling M, Wenqian B, Zailiang L (2017) Post-traumatic stress disorder and its predictors among bereaved Tibetan adolescents four years after the Yushu earthquake: A cross-sectional survey in China. J Clin Nurs 26: 1095-1105.

15. Arnberg FK, Johannesson KB, Michel P (2013) Prevalence and duration of PTSD in survivors 6 years after a natural disaster. J Anxiety Disord 347-352.

16. Javier RA, Marcos LR (1989) The role of stress on the language-independence and code-switching phenomena. J Psycholinguistic Res 18: 449-472.

17. Selye H (1967) In Vivo: The case for Supramoleculer Biology, New York, W.W. Norton \& Company, USA.

18. Ikeda K (1998) Mid-longitudinal care for victims from the Great HanshinAwaji Earthquake (in Japanese). Nursing Research 31: 63-71.

19. Joseph S, Yule W, Williams R, Hodgkinson P (1994) Case histories and shorter communications: Correlates of post-traumatic stress at 30 months: The Herald of Free Enterprise disaster. Behavior Research and Therapy 32 521-524.

20. Herman JL (1992) Trauma and Recovery. New York: Basic Books, USA.

21. Herrman $\mathrm{H}$ (2012) Promoting mental health and resilience after a disaster. Journal of Experimental and Clinical Medicine 4: 82-87.

22. Kobayashi S (2014) Attempt to keep mental health of victims throughout questionnaire research for two and half years (in Japanese). The Japanese Psychiatric Nursing Society 57: 260-264.

23. Miyagi T (2017) A interview research to temporary housing developments in Rikuzentakata area of Iwate prefecture for sixth year. Journal of Human Services 17: 63-103. 